\title{
AXIAL LOAD AND MOMENT INTERACTION CHARTS FOR HIGH PERFOMANCE CONCRETE
}

Francisco Aguirre Torrico

\begin{abstract}
This paper presents non-dimensional design charts for High Performance Concrete (HPC). The more realistic stress-strain curves used were proposed by CEB - Bulletin d'Information 228. The development is made applying "Silva Jr.'s Method". The strain failure domains of HPC were defined considering the ultimate concrete strain and the strain that corresponds to the maximum stress. The resultant compression force in the equilibrium equations was obtained by integration of the area under the more realistic stress-strain curve. Non-dimensional interactive charts procedures and practical examples are obtained by using an algebraic and symbolic computer program.
\end{abstract}

Keywords: High Performance Concrete, Axial-Moment Design Charts, Strees-Strain Curves. 